\title{
Immune-Related Response Criteria
}

National Cancer Institute

\section{Source}

National Cancer Institute. Immune-Related Response Criteria. NCI Thesaurus. Code C148192.

A set of response criteria designed to capture additional response patterns observed with immune therapy beyond those described by Response Evaluation Criteria in Solid Tumors (RECIST) or WHO criteria. 